\title{
EDUCAÇÃO E PROMOÇÃO EM SAÚDE PARA EX-MORADORES DE RUA
}

\author{
Jussara Silva Soares ${ }^{1}$ \\ Renata Prata Cunha Bernardes Rodrigues ${ }^{2}$ \\ Maria de Lourdes Carvalho ${ }^{3}$
}

\begin{abstract}
RESUMO: A Casa de Acolhimento Santa Gemma Galgani está vinculada à Pastoral de Rua e, por meio de um trabalho voluntário, recolhe moradores de rua e oferece apoio para sua reinserção na comunidade. Na Casa, eles recebem moradia, alimentação, roupas e kit de higiene, e sua permanência no local está vinculada às regras de boa convivência. Foi nesse cenário que atividades de educação e promoção em saúde com caráter multidisciplinar foram desenvolvidas por alunos do curso de Odontologia, Psicologia e Medicina da Universidade Federal de Uberlândia. As atividades foram realizadas semanalmente com o intuito de informar e motivar mudanças de comportamento quanto à saúde geral, bucal e psicossocial. Os ex-moradores de rua participaram ativamente das ações propostas pelo grupo, o que demonstrou a vontade, o esforço e os planos em relação à mudança do estilo de vida e de aquisição de hábitos saudáveis. Além disso, a inserção e a participação de estudantes da área da saúde, advindos de outras realidades sociais, enriqueceu a comunidade do local e a academia, levantando problemas do cotidiano que extrapolam as atividades rotineiras intramuros da Universidade, permitindo uma visão crítica e humanística a fim de contribuir na formação de novos saberes e novas práticas em saúde.
\end{abstract}

PALAVRAS-CHAVE: Educação em saúde. Promoção da saúde. Morador de rua.

\section{Education and health promotion to the ex-homeless}

\begin{abstract}
Casa de Acolhimento Santa Gemma Galgani is related to Pastoral de Rua and through volunteer work, is gathering the homeless and offering them support to their possible inclusion into the community. Once in the house, they will receive not only dwelling, but also feeding, clothing and sanitation kits, having their permanency bounded to good coexistence rules. It was in this scene that activities regarding education and health promotion with multidisciplinary caliber were developed by dentistry students from the Federal University of Uberlândia. The activities were realized weekly with the intention of informing and motivating behavioral changes related to general, oral and psychosocial health. The ex-homeless participated actively in the actions proposed by the team; that showed willing, dedication and plans relating to changing their life style and the acquisition of healthy habits. Besides that, the insertion and participation of students of the health area, coming from other social realities, enriched the local community and the academy, showing daily problems that go beyond the University's common activities, allowing a more critical and human point of view, in order to contribute in the formation of new learning and new health practices.
\end{abstract}

\footnotetext{
${ }^{1}$ Acadêmica do curso de Odontologia da Universidade Federal de Uberlândia (jussarasilvasoares@yahoo.com.br).

2 Mestre em Odontologia Preventiva e Social pela Universidade Estadual Paulista Júlio de Mesquita Filho, professora assistente no curso de

Odontologia da Universidade Federal de Uberlândia (renatapcb@hotmail.com).

3 Doutora em Odontologia Preventiva e Social pela Universidade Estadual Paulista Júlio de Mesquita Filho, professora titular no curso de Odontologia da Universidade Federal de Uberlândia (mlourdes.carvalho@superig.com.br).

Em Extensão, Uberlândia, v. 12, n. 1, p. 159-167, jan. / jun. 2013. 
KEYWORDS: Health education. Health promotion. Homeless people.

\section{INTRODUÇÃO}

A Casa de Acolhimento Santa Gemma Galgani, vinculada à Pastoral de Rua, está localizada no bairro Aclimação, setor leste de Uberlândia, município de Minas Gerais. Por meio de doações e de um trabalho social voluntário, acolhe moradores de rua e oferece apoio para sua reinserção na sociedade. A Casa possui capacidade para acolher quatorze pessoas, que, necessariamente, devem ser maiores de 18 anos e do sexo masculino.

$\mathrm{Na}$ Casa, essas pessoas recebem moradia, alimentação, roupas e kit de higiene, e sua permanência no local está vinculada às regras de boa convivência. Há uma constante rotatividade de moradores, já que podem deixar a Casa quando quiserem ou permanecer pelo tempo que acharem necessário.

Geralmente, os moradores de rua são pessoas que não possuem mais documentos, trabalho formal ou moradia fixa. Também, se encontram com vínculos familiares e sociais muitas vezes rompidos, o que as conduzem a um estado de crescente degradação e vulnerabilidade. Esta situação é agravada pelas atuais polarizações econômicas, pela reestruturação demográfica e pelas novas dinâmicas do trabalho que criam uma situação propícia para a concentração de riqueza no mundo, particularmente no Brasil, deixando graves sequelas sociais sem a contrapartida do Estado diante da miserabilidade crônica da população. Mesmo que no Brasil existam soluções informais (e até ilícitas) para se enfrentar os problemas da falta de moradia - por meio da ocupação de áreas de mananciais e ocupação de prédios públicos -, ou do desemprego - por meio do trabalho informal, como é o caso dos ambulantes -, um grande número de pessoas acabam nas ruas devido a falta de políticas públicas de apoio (VARANDA; ADORNO, 2004).

Em decorrência desta situação os moradores de rua podem se envolver com a criminalidade, fato que os retira de uma situação de invisibilidade. A violência se apresenta como resposta à falta de reconhecimento social. Desta forma, passam a ser vistos como "bandidos" que devem ser banidos da sociedade para as prisões. Além disso, tem-se o consumo de álcool e drogas, que termina por afundar o usuário em desespero e vergonha (VIEIRA et al., 2011).

De acordo com os dados do Instituto Brasileiro de Geografia e Estatística (IBGE), apenas 5,2\% dos municípios brasileiros oferecem um serviço de acolhimento para a população de rua (IBGE, 2010). O próprio IBGE conduz um levantamento sobre a população de rua em todo o país. Os dados coletados também servirão de subsídio para a definição de políticas específicas para esse grupo pela Secretaria dos Direitos Humanos.

O acolhimento desses indivíduos é essencial, uma vez que o ato ou efeito de acolher expressa, em suas várias definições, uma ação de aproximação, um "estar com" e um "estar perto de", ou seja, uma atitude de inclusão (BRASIL, 2006). A partir desse ato de acolhimento a moradores de rua pela Casa é que foi possível o desenvolvimento de ações de educação e promoção em saúde. 
A educação em saúde tem sido considerada uma importante estratégia para promover a saúde das coletividades, seja por meio do desenvolvimento de habilidades pessoais para o autocuidado geralmente a partir de um modelo vertical de transmissão de informações -, visando à manutenção da saúde e a prevenção das doenças, seja por meio de processos de empoderamento pessoal e comunitário, objetivando capacitar as pessoas a lutar por melhorias de suas condições de vida (BUSS, 2000; MIALHE et al., 2009).

A educação é um instrumento de transformação social. Não só a educação formal, mas toda a ação educativa propicia a reformulação de hábitos, aceitação de novos valores e estimula a criatividade. Deve ser pensada como um processo capaz de despertar nas pessoas a consciência crítica das causas reais dos seus problemas e, ao mesmo tempo, criar condições para mudanças de hábitos e estilos de vida (RESENDE, 1986; BEZERRA et al.,1999). Assim, o processo educativo é essencial nas mudanças de comportamento necessárias à manutenção, aquisição e promoção da saúde (PETRY; PRETTO, 1999).

De acordo com Machado (2007), o conceito de promoção da saúde trata de processos que abrangem a participação de toda a população no contexto de sua vida cotidiana e não apenas das pessoas com risco de adoecer. Essa noção está baseada em um conceito de saúde, considerado como um estado positivo e dinâmico de busca de bem-estar, que integra os aspectos físicos e mentais (ausência de doença), ambiental, pessoal e social.

Neste sentido, o objetivo deste trabalho é descrever as atividades de educação em saúde, de caráter multidisciplinar, realizadas com ex-moradores de rua que residem na Casa de Acolhimento Santa Gemma Galgani.

\section{METODOLOGIA}

O projeto do qual decorreu este trabalho está vinculado a Pró-Reitoria de Graduação da Universidade Federal de Uberlândia (UFU), por meio do Programa de Bolsas de Graduação Edital $N^{o}$ 05/2010, tendo sido desenvolvido no período de setembro de 2010 a dezembro de 2011 .

Trata-se de um estudo descritivo no qual se fez um relato de experiência das atividades desenvolvidas na Casa Santa Gemma Galgani, envolvendo, além da professora coordenadora, doze alunos de diferentes cursos de graduação da UFU, sendo dois do curso de Medicina, sete do curso de Odontologia, dois do curso de Psicologia e um do curso de Administração.

As ações foram realizadas em diferentes momentos. Primeiramente, os membros do grupo visitaram a Casa com o objetivo de conhecer seus moradores e responsáveis e observar a estrutura física do local para planejamento das ações. Em seguida, realizaram-se reuniões semanais com o intuito de discutir e planejar as atividades educativas que seriam desenvolvidas e as estratégias e abordagens a serem utilizadas. Textos de apoio relacionados à temática "moradores de rua" que descrevem os motivos que os levam a sair de casa, os sentimentos, desejos e esperança em relação à vida foram utilizados e debatidos pelos membros do projeto. 
Visando não somente um trabalho assistencialista, com entrega de materiais para higiene, limpeza pessoale doméstica, massim, trabalharcomosmoradoresno sentidodehaverumamudançadeparadigma e hábitos, o projeto priorizou atividades como rodas de conversa, grupos operativos, discussões, debates educativos, considerando os três níveis de aprendizado: cognitivo, afetivo e psicomotor.

As atividades foram planejadas e apoiadas nos seguintes temas: saúde geral (hipertensão, diabetes, doenças sexualmente transmissíveis, parasitoses), saúde bucal (etiologia e prevenção da cárie, doenças periodontais e câncer bucal), saúde mental (dinâmicas para valorização do indivíduo, sua autoestima e promoção do autocuidado, além de momentos de reflexão em grupo e lazer).

Após cada atividade realizada, os alunos dialogavam com os moradores, destacando os pontos positivos e negativos da prática. Em encontros posteriores do grupo, as estratégias e a avaliação eram discutidas, com o intuito de melhorar a atuação com o grupo a cada semana.

Por ser um local de alta rotatividade, já que o morador da Casa é livre para sair quando quiser, os conteúdos e atividades mais importantes foram reaplicados para fixação das informações transmitidas aos moradores permanentes, bem como novas informações para os novos integrantes do local.

\section{DESENVOLVIMENTO}

O encontro semanal do grupo de alunos com os moradores da Casa estreitou o contato com eles, facilitando a interação e tornando possível a utilização de ferramentas para a transmissão do conhecimento em saúde, como: rodas de conversa, discussões, debates educativos e dinâmicas de grupo, todas desenvolvidas em um ambiente de respeito, confiança e atenção. Pretendeu-se estimular o autocuidado e a autoestima. Os trabalhos realizados foram divididos em três grandes temas: Saúde Geral, Saúde Bucal e Saúde Mental.

Noprimeiro semestre do projeto foram realizadas ações que privilegiaram temáticas como "saúde geral" e"saúdebucal".Paraaatividaderelacionadaà primeira temática, o grupoorganizouumaroda de conversa guiada por slides utilizando data show. Os conteúdos abordados priorizaram doenças relacionadas à falta de higiene pessoal, bem como a prevenção delas por meio de uma higiene bem executada.

Um dos encontros foi dedicado ao tema "hipertensão", em que foram abordados os seguintes aspectos: definição de circulação sanguínea, funcionamento do coração como bomba, definição de pressão arterial, explicação sobre os níveis normais de pressão sanguínea e sobre quando alterados. Discutiram-se os fatores de risco e as medidas preventivas. Ao final, foi entregue, a cada morador, uma cartilha relacionada ao tema.

Para a temática Saúde Bucal, o grupo organizou uma de roda de conversa guiada por slides utilizando data show e, com auxílio de macro modelos dentais, explanou-se sobre o tema "higienização bucal". Ao fim da palestra, foram distribuídos fios dentais, pastas dentais e escovas de dente (Figura 1) 
Fig. 1 - Morador utilizando o fio dental pela primeira vez.

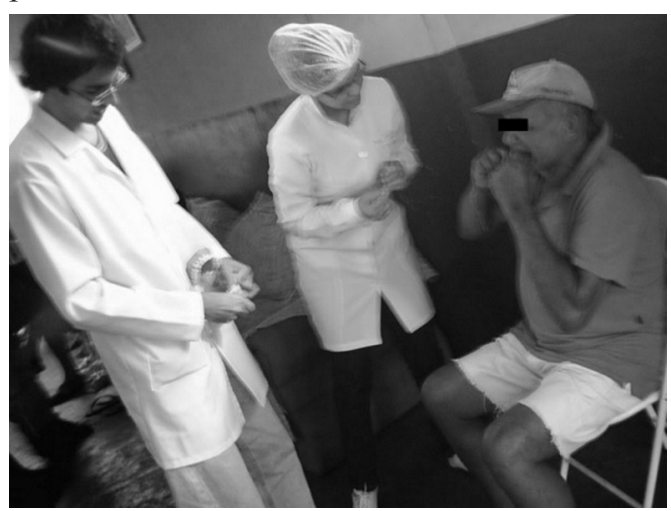

Fonte: Acervo do projeto.

Outra atividade desenvolvida foi uma apresentação do filme "À procura da felicidade" (2006). A película aborda a história de um homem obstinado que luta para sobreviver e sustentar seu filho mesmo sob as mais árduas circunstâncias, sem que isso o faça ignorar os principais valores nem perder a esperança. Após a exibição, o grupo realizou uma roda de conversa sobre o tema. Alguns relatos de moradores enfatizaram a importância da atividade:

[...] o filme foi bom porque ajuda a melhorar a concentração, pensar em outras coisas (distração) (Morador 1).

[...] é um exemplo para todos nós que estamos aqui [...] ajuda a animar para a vida [...] (Morador 2)

[...] gostei do filme e gostaria de ver mais filmes [...] (Morador 3).

As atividades do primeiro semestre foram encerradas com uma confraternização natalina. Neste encontro, foi realizada uma dinâmica, na qual cada morador recebeu uma folha em branco para que desenhasse algo sobre o significado do Natal. Após essa atividade, cada um explicou seu desenho, que foi utilizado na confecção de cartões natalinos a serem entregues juntamente com um kit de higiene conseguido por meio de doações (Figura 2).

Figura 2 - Confraternização de Natal.

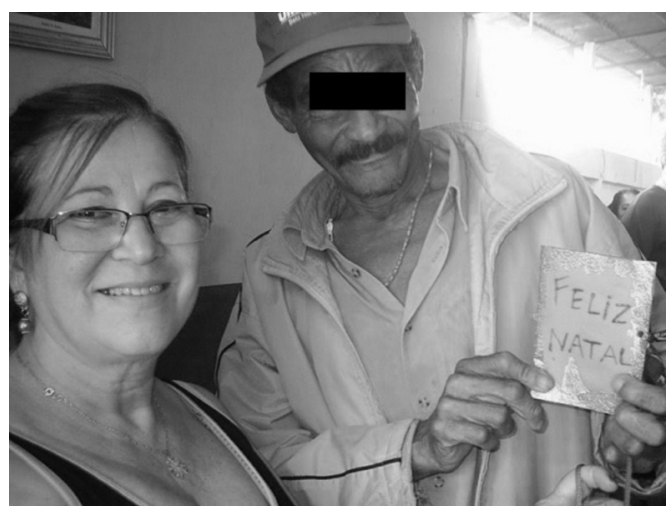

Fonte: Acervo do projeto. 
No segundo semestre, a equipe de trabalho deparou-se com a ausência de moradores antigos e com a presença de novos moradores. As atividades de educação em saúde, realizadas no semestre anterior, foram aplicadas novamente, mas, desta vez, em outro local. Em vez de utilizar a parte interna da Casa, as ações foram desenvolvidas na parte externa (que conta com sofás e cadeiras) com a finalidade de promover uma maior integração dos moradores, proporcionandolhes um melhor convívio, valorizando a amizade e o respeito mútuo. Mais uma vez, atividades relacionadas à temática "saúde mental" foram trabalhadas, por meio das seguintes dinâmicas:

Dinâmica de grupo relacionada à saúde - os moradores ficaram livres para relatarem sobre sua infância, sua comida favorita, seu animal preferido, prática de esportes, se considera sua saúde boa, o que gosta de fazer para descontrair e o que admira em uma pessoa. Houve uma ampla discussão com a participação de todos os moradores e, para os que faziam uso de medicamentos, foram confeccionadas caixas personalizadas para a guarda desses medicamentos.

Dinâmica do barbante: teve como objetivo reforçar a união entre os moradores da Casa. Para isso, foi utilizado um rolo de barbante, passado de um por um e de forma alternada. A cada pessoa lhe era perguntado o que poderia fazer para ajudar na convivência da Casa, de forma que, ao final, uma grande teia de barbante foi formada. Um dos aspectos mais relatados nessa dinâmica foi a dificuldade de muitos para vencer o vício. Alguns relataram que a presença da equipe do projeto dava-lhes força e apoio nessa luta.

Dinâmica do corpo de jornal: os moradores foram divididos em grupos, aos quais foram distribuídos materiais como jornais, colas, tesouras e canetas para que representassem o corpo humano. O grupo que, de forma separada, representou o corpo, ao juntar as partes, pode verificar que o mesmo estava deformado, composto por partes pequenas e outras, muito grandes. Já o grupo que trabalhou de forma conjunta, representou o corpo proporcional e uniformemente. $\mathrm{O}$ objetivo dessa dinâmica foi valorizar o trabalho em equipe, pois, quando se trabalha em grupo, as chances de se obter sucesso são maiores.

Dinâmica das fitas coloridas: visou orientar sobre as doenças sexualmente transmissíveis (DSTs). Cada participante tinha cinco fitas de uma única cor. Ao som de músicas, essas fitas podiam ser trocadas entre eles, de acordo com sua vontade. As músicas proporcionaram uma descontração no ambiente. Ao término da atividade, cada participante estava com cores variadas de fitas nas mãos e, a partir dessa troca, o grupo explicou sobre os riscos de contágio das DSTs e uma cartilha ilustrada lhes foi entregue.

Em outro encontro, comemorou-se a Páscoa com um lanche. Um violeiro tocou músicas sugeridas pelos moradores. Percebeu-se que, além da parte educativa, os participantes do projeto levaram alegria, atenção e carinho àquelas pessoas.

Também houve uma visita ao Parque do Sabiá, agendada em um dos encontros. Todos os moradores compareceram ao passeio, mesmo aqueles que apresentavam dificuldades de locomoção. A atividade proporcionou lazer e satisfação ao grupo (Figura 3). 
Figura 3 - Passeio ao Parque do Sabiá, Uberlândia-MG.

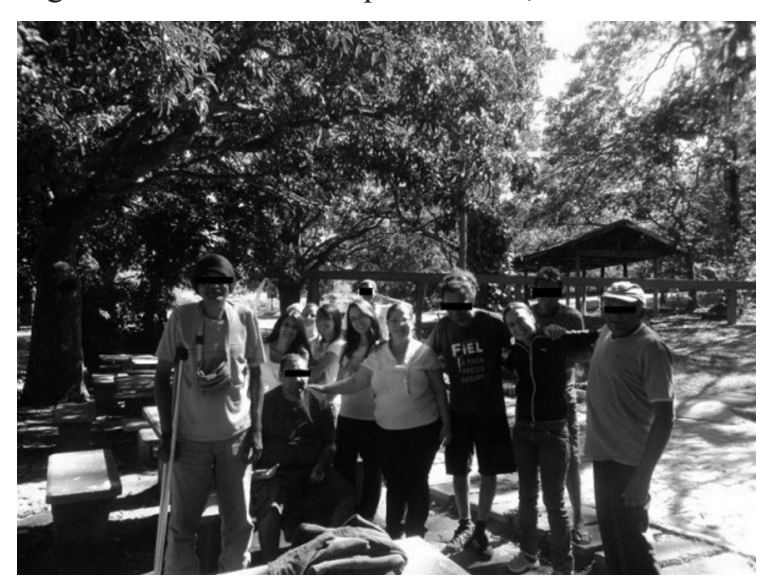

Fonte: Acervo do projeto.

No terceiro semestre do projeto, os participantes do projeto perguntaram aos moradores sobre as atividades que eles gostariam que fossem repetidas. Eles disseram que as melhores ações foram a da tarde com música e a do passeio ao parque. Também relataram que as atividades em grupo haviam melhorado o convívio na Casa. Desta forma, dinâmicas e atividades educativas em saúde feitas nos semestres anteriores foram trabalhadas com os moradores novamente. Também foram incorporadas novas atividades, como:

Contação de estórias por meio de recortes: foram distribuídas revistas aos moradores que deveriam recortar figuras interessantes e as colar numa folha em branco. Ao término da atividade, o grupo criava uma estória com as gravuras. As figuras mais utilizadas foram: carros, mulheres, dinheiro, viagem, praia, família, paisagens, pessoas famosas, pessoas sorrindo, dentre outras.

Palavras cruzadas: as palavras trabalhadas foram referentes à temática relacionada à saúde geral. Além de ser uma distração, a atividade também ajudou no reforço das mensagens transmitidas. Foram utilizadas as seguintes frases na atividade:

A ingestão de muito sal pode causar (hipertensão)

A ingestão de muito açúcar pode causar (diabetes)

Fazer caminhadas faz bem para o . (coração)

Conversar, assistir a filmes, ler, exercitar o corpo, dormir bem e se alimentar bem ajuda a manter a saúde . (mental)

É importante escovar os dentes sempre depois das (refeições)

Nunca se deve esquecer de escovar a língua para evitar o . (mau hálito)

Passar fio dental e escovar os dentes ajuda na prevenção das . (cáries)

Para prevenir a AIDS é importante utilizar . (preservativo)

Devemos colocar apenas o que vamos comer no prato para evitar o (desperdício) 
Tomar os (remédios) regularmente e nos horários certos ajudam a manter nossa saúde.

Ler a (Bíblia) faz bem para o espírito.

Sempre devemos (ajudar) o próximo.

Quem tem amigos tem um . (tesouro)

Devemos ser sempre cordiais e (prestativos) com as pessoas.

Sempre devemos manter nossas coisas . (organizadas)

Sempre devemos tratar a todos com (educação)

É importante lavar os (alimentos) antes de comer.

Nunca devemos comer antes de lavar as nossas . (mãos)

Tomar banho, lavar os cabelos e cortar as unhas é importante para manter nossa (higiene)

Trabalhar em grupo é muito vantajoso, pois as tarefas. (dividimos)

Em um dos encontros, foi discutida a importância de uma alimentação saudável, especificamente a ingestão de frutas. Uma explicação sobre os benefícios de cada fruta foi realizada. Os moradores foram orientados em relação ao custo e, por isso, a importância de se valorizar as frutas da época, mais acessível. Depois da explanação, frutas foram lavadas, picadas e transformadas em uma deliciosa salada de frutas, saboreada por todos.

As atividades do projeto foram encerradas no final do mês de dezembro de 2011, quando, novamente, realizou-se uma confraternização natalina com lanche e distribuição de kits de higiene.

\section{CONSIDERAÇÕES FINAIS}

Os ex-moradores de rua participaram ativamente das ações propostas pelo grupo, o que demonstrou a vontade, o esforço e os planos em relaçãoà mudança do estilo de vida e de aquisição de hábitos saudáveis.

Além disso, a inserção e a participação de estudantes da área da saúde, advindos de outras realidades sociais, enriqueceu a comunidade do local e a própria academia, por levantarem problemas do cotidiano, extrapolando as atividades rotineiras intramuros da Universidade, permitindo-lhes uma visão mais crítica e humanística de forma a contribuir na formação de novos saberes e novas práticas em saúde.

A relevância do projeto aponta a necessidade de uma ação continuada, ou seja, retornar a este local para verificar a prática da aquisição de hábitos saudáveis para uma melhor qualidade de vida dessas pessoas, buscando referenciais para novas propostas de um trabalho de investigação no campo da extensão universitária. 


\section{REFERÊNCIAS}

BEZERRA, A. C. B. et al. Promoção de saúde bucal. 2 ed. São Paulo: Artes Médicas, 1999.

BRASIL. Governo quer detalhar a vida dos moradores de rua no país. Brasília, 2012. Disponível em: <http:/www.brasil.gov.br/noticias/arquivos/2012/03/12/governo-quer-detalhara-vida-dos-moradores-de-rua-no-pais >. Acesso em: 28 jun. 2012.

. Ministério da Saúde. Secretaria de Atenção à Saúde. Núcleo Técnico da Política Nacional de Humanização. Acolhimento nas práticas de produção de saúde. Brasília, 2006. 44p. Disponível em: < http://portal.saude.gov.br/portal/arquivos/pdf/APPS_PNH.pdf > Acesso em: 28 jun. 2012.

BUSS, P. M. Promoção da saúde e qualidade de vida. Ciênc. Saúde Coletiva. Rio de Janeiro, v. 5, n. 1, p. 163-177, 2000. Disponível em: <http://www.scielo.br/scielo.php?script=sci arttext\&pid=S1413-81232000000100014\&lng=pt\&nrm=iso>. Acesso em: 28 jun. 2012.

INSTITUTO BRASILEIRO DE GEOGRAFIA E ESTATÍSTICA. 98,6\% dos municípios declararam possuir serviços socioassistenciais, mas poucos supervisionam. 2010. Disponível em: <http://www.ibge.gov.br/home/presidencia/noticias/noticia_visualiza.php?id_ noticia $=1620 \& i d \_p a g i n a=1>$. Acesso em: 28 jun. 2012.

MACHADO, M. F. A. S. et al. Integralidade, formação de saúde, educação em saúde e as propostas do SUS: uma revisão conceitual. Ciênc. Saúde Coletiva, Rio de Janeiro, v. 12, n. 2, p. 335-342, 2007. Disponível em: $<$ http://www.scielo.br/scielo.php?script=sci_arttext\&pid $=$ S1413-81232007000200009>. Acesso em: 28 jun. 2012.

MIALHE, F. L. et al. Educação em saúde. In: PEREIRA, A. C. (Org.). Tratado de saúde coletiva em odontologia. Nova Odessa: Napoleão, p. 441-486, 2009.

PETRY, P. C.; PRETTO, M. S. Educação e motivação em saúde bucal. In: ABOPREV. 2 ed. São Paulo: Artes Médicas, 1999.

RESENDE, A. L. M. Saúde dialética do pensar e do fazer. São Paulo: Cortez. 1986.

VARANDA, W.; ADORNO, R. C. F. Descartáveis urbanos: discutindo a complexidade da população de rua e o desafio para políticas de saúde. Saúde e Sociedade, São Paulo, v.13, n.1, p.56-69, jan.-abr. 2004.

VIEIRA, E. D. et al. Grupos de encontro com moradores de rua da cidade de Jataí - GO: uma experiência psicodramática. Revista Eletrônica Itinerarius Reflectionis, Jataí, v.1 n.10, 2011. Disponível em: < http://revistas.jatai.ufg.br/index.php/itinerarius > . Acesso em: 29 mar. 2012. 